\title{
Nontraditional Student Access and Success in Engineering
}

\author{
Mrs. Jacqueline Bushey-McNeil, Purdue University, West Lafayette
}

Jacqueline Bushey-McNeil is a doctoral student in the Purdue University Department of Engineering Education. She has a bachelor's degree in Mining Engineering and a Master's degree in Engineering Management, in which she was a mentored and tutored American Indian students in the Tiospaye Program, a program to help American Indians earn degrees in engineering, science, and math. Her dissertation topic is on engineering faculty, quality teaching, and how climate affects their pedagogy choices. She is also interested in nontraditional students' access and success in engineering education and is investigating this topic at Purdue University.

\section{Dr. Matthew W. Ohland, Purdue University and Central Queensland University}

Matthew W. Ohland is Professor of Engineering Education at Purdue University and a Professorial Research Fellow at Central Queensland University. He has degrees from Swarthmore College, Rensselaer Polytechnic Institute, and the University of Florida. His research on the longitudinal study of engineering students, team assignment, peer evaluation, and active and collaborative teaching methods has been supported by over $\$ 12.8$ million from the National Science Foundation and the Sloan Foundation and his team received Best Paper awards from the Journal of Engineering Education in 2008 and 2011 and from the IEEE Transactions on Education in 2011. Dr. Ohland is past Chair of ASEE's Educational Research and Methods division and a member the Board of Governors of the IEEE Education Society. He was the 2002-2006 President of Tau Beta Pi.

\section{Mr. Russell Andrew Long, Purdue University, West Lafayette}

Russell Long is Director of Project Assessment at the Purdue University School of Engineering Education. He has extensive experience in assessment and student services in higher education and has worked for eight years as the Data Steward of the MIDFIELD project. 


\title{
Nontraditional Student Access and Success in Engineering
}

\begin{abstract}
There is a shortage of baccalaureate engineering majors in the United States. Engineering institutions need to attract more students. The National Science Board has published a detailed report about the importance of maintaining and increasing the number of Science, Technology, Engineering, and Math (STEM) majors in the U.S. to stay competitive in this increasing global economy. Nontraditional students could be a huge, potential source of engineers in the United States. The number of nontraditional students is increasing in higher education but is still a small population in engineering. Private, for profit institutions have been very popular and have attracted many nontraditional students, with their enrollment of nontraditional students reaching $89 \%$. Nontraditional students have been studied in community colleges and urban universities, but have been rarely studied at public 4-year universities in engineering due to a lack of longitudinal data on individual students. We studied nontraditional students using the MultipleInstitution Database for Investigating Engineering Longitudinal Development (MIDFIELD). MIDFIELD is large enough to provide a better understanding of nontraditional students in public 4 year universities, identify conditions where they are more numerous and more successful, and explore the conditions that support their success. MIDFIELD is a longitudinal, multiinstitutional, and multivariate dataset of over 209,737 engineering students. In this research, we examine nontraditional and traditional students that may be similar or different in outcomes and demographics. The focus is on engineering, rather than all the Science, Technology, Engineering and Mathematics (STEM) disciplines, because engineering is different from science, technology, and mathematics. The reported results are representative of large public institutions that have engineering departments and colleges. The universities in our data are a good representation of the U.S. engineering Bachelor of Science (B.S.) degrees. This research informs the process of broadening participation in engineering to increase the quantity and diversity of engineering baccalaureate degree recipients.
\end{abstract}

Specifically, this research helps us understand the demographics and outcomes of nontraditional engineering students. Results from the research show that nontraditional students are $10 \%$ of the undergraduate engineering population from 1988 to 2002 . We find that $37 \%$ of traditional students who switch into engineering graduate in engineering, whereas only $16 \%$ of nontraditional students who switch into engineering make it to graduation. This suggests that nontraditional students face additional barriers that limit their ability to switch into engineering.

This inquiry will lead to the identification of practices that promote the access and success of a larger and more diverse population of nontraditional students. 


\section{Introduction}

There is a shortage of baccalaureate engineering majors in the United States. A way for engineering institutions to attract more people to engineering is not to recruit engineering students that are not interested, but to look at people that do not fit the traditional profile, nontraditional students. The National Science Board has published a detailed report about the importance of maintaining and increasing the number of Science, Technology, Engineering, and Math (STEM) majors in the U.S. to stay competitive in this increasing global economy. ${ }^{1,2}$ Nontraditional students could be a huge, potential resource for the U.S.'s growing need for engineers. The number of nontraditional students is increasing in higher education but is still a small population in engineering. ${ }^{3}$ Private, for profit institutions have been very popular and have attracted many nontraditional students, with their enrollment of nontraditional students reaching 89\%. ${ }^{3}$ Nontraditional students have been studied in community colleges and urban universities, but have been rarely studied at public 4-year universities in engineering due to a lack of longitudinal data on individual students.

The research of nontraditional students used the Multiple-Institution Database for Investigating Engineering Longitudinal Development (MIDFIELD). MIDFIELD was large enough to provide a better understanding of nontraditional students in public 4 year universities, identified conditions where they are more numerous and more successful, and explored the conditions that support their success. MIDFIELD is a longitudinal, multi-institutional, and multivariate dataset of over 209,737 engineering students.

In this study we examined nontraditional and traditional students that were similar and different in demographics. The focus will be on engineering, rather than all the Science, Technology, Engineering and Mathematics (STEM) disciplines, because engineering is different from science, technology, and mathematics. ${ }^{4}$ The reported results are representative of large public institutions that have engineering departments and colleges. The universities in our data are a good representation of the U.S. engineering Bachelor of Science (B.S.) degrees. ${ }^{5}$ This research informed the process of broadening participation in engineering to increase the quantity and diversity of engineering baccalaureate degree recipients.

The long-term goal of this research is to identify pathways to diversify the composition of the engineering profession and to increase the academic and professional success of engineering undergraduates from a broad range of backgrounds, interests, and experiences. MIDFIELD had a legacy of exploring questions of great interest to the engineering education community using evidence from a large-population longitudinal dataset. 


\section{What makes a student "nontraditional"?}

Students have been identified as "nontraditional" according to various characteristics that make them different from the larger "traditional" population. The term "nontraditional" focuses on characteristics that differentiate students on the basis of life experiences and choices, rather than on the basis of demographic characteristics such as race/ethnicity and gender. The National Center for Educational Statistics has defined the following characteristics as nontraditional: ${ }^{3}$

- Delaying enrollment in higher education

- Attending part-time for at least part of the academic year

- Working 35 hours or more hours per week while enrolled

- Being financially independent for financial aid purposes

- Having non-spousal dependents

- Being a single parent (a special case of having non-spousal dependents)

- Not having a high school diploma

Commonly cited figures that $73 \%$ of all undergraduates have at least one of these characteristics are misleading, because nontraditional students - especially certain types of nontraditional students - are much more likely to attend two-year colleges and may never transfer to four-year institutions. At public four-year institutions such as those included in MIDFIELD, $43 \%$ of students have none of these characteristics, $20 \%$ have one, $23 \%$ have two or three, and $14 \%$ have four or more. An even higher fraction (50\%) of students at private four-year institutions fall into the "traditional" population. Although the listed characteristics do not include "being older than 25 years of age", the NCES report describes students 25 years old or older as being of nontraditional age. Many other researchers use the same definition, but describe nontraditional students as being over the age of $24 .^{6,7,8,9,10,11,12}$ This is the definition that will be used in the present study. Other researchers have also included commuter students as nontraditional. ${ }^{12,13}$

\section{Nontraditional students enrolled in U.S. engineering programs}

Undergraduate engineering enrollments in the U.S. include a small and diminishing number of nontraditional students, although overall enrollment is growing. Engineering is not known for having nontraditional students, but many institutions in higher education are growing in their nontraditional student enrollment. ${ }^{3}$ Recent data shows that $89 \%$ of students in private for-profit institutions are nontraditional. ${ }^{3}$ Many nontraditional students are transferring previous credits into engineering programs at high percentages ranging from $79 \%$ to $100 \%$. There is very little research on nontraditional students who transfer into engineering. We know very little about this population, their demographics, and their experiences. Many nontraditional students are transfer students, so they may be susceptible to transfer shock, a disruption when transferring to a new institution ${ }^{14}$ that results from academic, psychological, sociocultural, informational, financial and other barriers. ${ }^{15,16}$ Nontraditional students may be less resilient to the effects of transfer shock. 


\section{The benefits of studying nontraditional students}

Another benefit of studying access of nontraditional students in U.S. undergraduate engineering programs is what such a study might reveal about the engineering education system. Nontraditional students are in some ways at the margins of the cultural aspect of institution, so their choice of engineering in spite of the additional barriers to entry that result from being nontraditional suggest that they may be more intrinsically interested in learning engineering. ${ }^{17,18}$ The extent to which the choices and outcomes of nontraditional students result from a sense of being "outsiders" can provide valuable information about what it means to be a part of a new culture and what it means to be an "insider" in the institution and in engineering. ${ }^{19}$

A variety of benefits have been identified as a result of enrolling nontraditional students, including some that result from encounters between nontraditional and traditional students. Older students have more certainty with their choice in major, ${ }^{20,21,22}$ which leads to higher persistence. ${ }^{23}$ Nontraditional and female students have greater GPAs and greater decidedness. ${ }^{24}$ Female nontraditional students in particular had better psychological functioning when compared to traditional students. ${ }^{25}$ A better understanding of the dynamics of access, performance, and success of nontraditional students is expected to result in improvements for both nontraditional and traditional students.

\section{Data and Method}

MIDFIELD was created as a successor to that earlier database to include more current data and additional data elements. ${ }^{26}$ MIDFIELD includes demographic, enrollment, course performance, and graduation data and has grown by adding new partner institutions and through updates. Data are placed in a common format to facilitate cross-institutional studies. A data dictionary and a sample Memorandum of Understanding are published online. ${ }^{27}$ MIDFIELD comprises whole population data for undergraduate, degree-seeking students - those who matriculate in engineering, those who switch into engineering from other majors, students who come to engineering as transfer students, part-time engineering students, and students who have never enrolled in engineering. This results in a dataset that comprises more than 1,000,000 unique undergraduate, degree-seeking students at 11 institutions. Of those, more than 200,000 were ever enrolled in engineering, and more than 85,000 graduated with a degree in engineering.

MIDFIELD institutions award more than $10 \%$ of all U.S. engineering bachelor's degrees annually and includes two historically black colleges and universities (HBCUs). MIDFIELD does not include any Hispanic Serving Institutions (HSIs) at this time. None of the current MIDFIELD partner institutions has significant numbers of Latino engineering students, so the data indicating traditional and nontraditional students by ethnicity is skewed towards black engineering students and away from Latino/Hispanic students. Even acknowledging this 
limitation, MIDFIELD is large enough to support disaggregated analyses and contains longitudinal information on each student to avoid the limitations inherent in cross-sectional data or in the construction of synthetic cohorts. In that sense, while the racial/ethnic distribution of MIDFIELD does not match a national sample, conclusions regarding Hispanic students are likely representative of the experience of Hispanics in Predominately White Institutions. The current MIDFIELD partner institutions are large public universities in which over 20 percent of students major in engineering, versus the nine percent national average among institutions with engineering programs. ${ }^{28}$ Results are most likely to generalize to the same type of institutionlarge public universities with above-average enrollment of engineering students - and therefore are relevant to institutions producing most engineering graduates nationally. ${ }^{5}$

Relevant to the current study, MIDFIELD includes data from 6,330 engineering students who are over the age of 24, of whom 2,751 graduated in engineering. Many more students - 17,069 students ever enrolling in engineering - were classified as part time students. There are 1,678 students who are in both groups, which will allow some exploration of different degrees of nontraditional status as defined in an earlier NCES study. ${ }^{29}$ Thus, the MIDFIELD database includes 21,721 students who were either over the age of 24 or enrolled part time, comprising $10 \%$ of the 218,901 students in the database who ever enrolled in engineering. These numbers are large enough to permit meaningful analysis and are even large enough to disaggregate to explore effects by race/ethnicity, gender, discipline, and institution - although it will not be possible to disaggregate by all four simultaneously. Some MIDFIELD institutions enroll reasonable numbers of commuter students, but MIDFIELD does not include a designation to identify those students. While a data correction may be possible, there is likely a high degree of overlap between commuter and part-time students, so it is unlikely that this will add significantly to the population of nontraditional students available for study.

A data update is underway that will add to these totals, and new institutional partners may further extend the reach of the dataset. A further 52,131 engineering students are included in MIDFIELD for whom no age was reported, of whom 14,807 graduated in engineering. We will seek data updates to fill in values where data are currently missing. Nontraditional student enrollments are certainly not distributed uniformly by institution — on average, $4-5 \%$ of student enrollment is nontraditional by age, but the percentages range from $1 \%$ to $25 \%$ by institution. Adding to institutional variability, nontraditional students enter exclusively as transfer students at some institutions, while at other institutions $25 \%$ of first-time-in-college students are of nontraditional age. The nontraditional student body is $20 \%$ female, which is typical of U.S. engineering enrollments. 


\section{Results and Discussion}

\section{Nontraditional student access and completion}

Table 1 shows that the $10 \%$ fraction of nontraditional students is relatively stable over a large number of cohorts. While the NCES reports that $33 \%$ of undergraduates enrolled part time for at least one semester, ${ }^{3}$ the MIDFIELD designation that a student is part time is one assigned by the institution as a characteristic of the student rather than one that changes each semester based on the student's credit load, so the actual incidence of part-time enrollment using the NCES definition would be higher. Similarly, the NCES definition of delayed enrollment is based on whether a student enrolls in undergraduate education in the same year they graduate high school, which is more encompassing than the definition based on a student being age 25 or older at matriculation. Again, therefore, the actual incidence of delayed graduation using the NCES definition would be higher. MIDFIELD contains no data to create an operational definition of any of the other nontraditional characteristics. As a result of these different definitions, it is difficult to determine to what extent the MIDFIELD institutions are representative of other public four-year institutions in the United States.

Table 1: The nontraditional fraction of students matriculating and graduating in engineering.

\begin{tabular}{c|c|c|c}
\cline { 2 - 3 } & \multicolumn{2}{|c|}{$\begin{array}{c}\text { Engineering matriculants graduating in } \\
\text { engineering }\end{array}$} & $\begin{array}{c}\% \\
\text { Nontraditional }\end{array}$ \\
\cline { 2 - 3 } Cohort & Nontraditional & Total & $12 \%$ \\
\hline $1987 / 88$ & 335 & 2769 & $6 \%$ \\
$1988 / 89$ & 237 & 3911 & $7 \%$ \\
$1989 / 90$ & 281 & 4192 & $9 \%$ \\
$1990 / 91$ & 499 & 5282 & $9 \%$ \\
$1991 / 92$ & 473 & 5274 & $10 \%$ \\
$1992 / 93$ & 530 & 5257 & $10 \%$ \\
$1993 / 94$ & 497 & 5183 & $9 \%$ \\
$1994 / 95$ & 465 & 5095 & $10 \%$ \\
$1995 / 96$ & 455 & 4748 & $11 \%$ \\
$1996 / 97$ & 515 & 4831 & $10 \%$ \\
$1997 / 98$ & 504 & 4946 & $10 \%$ \\
$1998 / 99$ & 450 & 4726 & $9 \%$ \\
$1999 / 00$ & 449 & 4856 & $10 \%$ \\
$2000 / 01$ & 358 & 3725 & $12 \%$ \\
$2001 / 02$ & 284 & 2373 &
\end{tabular}

Of the 6,330 nontraditional students ever enrolled in engineering, $80 \%$ started in engineering, compared to $87 \%$ of traditional students - yet equal fractions of graduates in both populations started in engineering. It may be that nontraditional students who switch into engineering are not prepared for it or that nontraditional students explore a wider range of academic pathways before 
selecting a major. These possibilities raise interesting questions about nontraditional students and their fit with engineering and highlight the need for further study. Considering students who switch into engineering after matriculating in other disciplines, another important question arises. While $37 \%$ of traditional students who switch into engineering graduate in engineering, only $16 \%$ of nontraditional students who switch into engineering make it to graduation. This suggests that nontraditional students face additional barriers that limit their ability to switch into engineering. It will be particularly valuable to explore which disciplines provide paths to success for nontraditional students, particularly since the NCES reports that the student profile in the United States is increasingly nontraditional by these definitions. Nontraditional engineering students are significantly more likely to have entered MIDFIELD institutions as transfer students. While $19 \%$ of traditional students are transfers, $58 \%$ of nontraditional students are.

\section{Nontraditional students and the transfer pathway}

Transfer students have attended another institution before being admitted to their current university. Typical of MIDFIELD studies, institutional definitions prevail - a student is designated as a first-time student or a transfer student when the institution transmits the data. Generally, a student is a transfer student if 30 or more credits are transferred to the receiving institution from a single previous institution. As a result, students may receive large numbers of credits from Advanced Placement, dual enrollment, and other pathways and still be designated as a first-time-in-college student. Table 2 shows that the fraction of the nontraditional population entering as transfers varies by institution from $26 \%$ to $94 \%$. Institutions with a higher fraction of nontraditional students tend to enroll a lower fraction of nontraditional students through the transfer pathway_-some institutions seem to have policies or recruiting procedures that reach out to nontraditional students beyond the transfer pathway.

Table 2: Institutions with more nontraditional students rely less on the transfer pathway.

\begin{tabular}{c|c|c} 
& $\begin{array}{c}\text { Transfer fraction of } \\
\text { Institution } \\
\text { of engineering students }\end{array}$ & $\begin{array}{l}\text { Toditional fraction } \\
\text { nontraditional engineering } \\
\text { students }\end{array}$ \\
\hline A & $8 \%$ & $94 \%$ \\
B & $15 \%$ & $92 \%$ \\
C & $2 \%$ & $90 \%$ \\
D & $6 \%$ & $75 \%$ \\
E & $7 \%$ & $70 \%$ \\
F & $10 \%$ & $68 \%$ \\
G & $18 \%$ & $66 \%$ \\
H & $14 \%$ & $54 \%$ \\
I & $11 \%$ & $42 \%$ \\
J & $12 \%$ & $31 \%$ \\
K & $28 \%$ & $26 \%$
\end{tabular}




\section{The diversity of nontraditional students}

Nontraditional students contribute to the diversity of an institution, to the engineering student body, and the engineering profession after graduation. It is relevant to ask whether nontraditional students are more diverse than traditional students on other measures. As discussed earlier, the $20 \%$ of nontraditional students are female, typical of the traditional students. As in our earlier work, however, there are interesting results when the intersection of race/ethnicity and gender are considered. Table 3 shows the distribution of race/ethnicity and gender of the nontraditional and traditional engineering students. Native American, Other, and Unspecified are omitted.

Table 3: The demographics of nontraditional and traditional engineering students.

\begin{tabular}{l|c|c}
$\begin{array}{l}\text { Race/ethnicity and } \\
\text { Gender }\end{array}$ & $\begin{array}{c}\text { Nontraditional } \\
\text { engineering } \\
\text { students }\end{array}$ & $\begin{array}{c}\text { Traditional } \\
\text { engineering } \\
\text { students }\end{array}$ \\
\hline White Male & $54 \%$ & $59 \%$ \\
White Female & $17 \%$ & $17 \%$ \\
Black Male & $9 \%$ & $6 \%$ \\
Asian Male & $4 \%$ & $5 \%$ \\
International Male & $4 \%$ & $4 \%$ \\
Black Female & $4 \%$ & $4 \%$ \\
Hispanic Male & $3 \%$ & $3 \%$ \\
Asian Female & $1 \%$ & $2 \%$ \\
Hispanic Female & $1 \%$ & $1 \%$ \\
International & & \\
Female & $1 \%$ & $1 \%$
\end{tabular}

Nontraditional and traditional engineering students have a similar distribution of race/ethnicity and gender. A careful examination reveals that the nontraditional population has a lower fraction of White males and Asian students and concomitant gains in the fraction of Black males. Noting the severe underrepresentation of Black males and their low graduation rates in engineering, ${ }^{30}$ nontraditional students may represent an untapped source of this underserved population.

\section{Conclusions}

The findings here begin to enhance our understanding of the access and success of nontraditional students and their impact on the traditional student enrollment. Furthermore, our findings raise a number of issues that suggest that further study will be valuable in identifying institutions, programs, and policies that are favorable with respect to the access and success of nontraditional students. 


\section{References}

${ }^{1}$ The Science and Engineering Workforce/ Realizing America's Potential. (2003). NSB 03-69, National Science Board, Washington, DC, August 14.

${ }^{2}$ National Academy of Science Committee on Science, Engineering and Public Policy. (2006). Rising Above the Gathering Storm: Energizing and Employing America for a Brighter Economic Future. Washington, D.C.: National Academies Press.

${ }^{3}$ Choy, S. (2002). Nontraditional Undergraduates (NCES 2002-012). Washington, DC: US Department of Education. National Center for Education Statistics.

${ }^{4}$ Ohland, M.W., S.D. Sheppard, G. Lichtenstein, O. Eris, D. Chachra, and R.A. Layton, "Persistence, Engagement, and Migration in Engineering," invited to "Educating Engineers: Who, What, and How," a special issue of J. Eng. Ed. 97(3), July 2008.

5 American Society for Engineering Education. (2012). Degrees awarded and enrollment reports. ASEE Engineering Data Management System. ASEE: Washington, DC. http://www.asee.org/datamining/reports/

${ }^{6}$ Sandler, M. E. (2000). A Focal Examination of Integration, Commitment, and Academic Performance: Three Subsystems from the Integrated Model of Student Persistence with Sociostructural Background Variable Effects.

${ }^{7}$ Rosenthal, G. T., Folse, E. J., Alleman, N. W., Boudreaux, D., Soper, B., \& Von Bergen, C. (2000). The One to One Survey: Traditional Versus Nontraditional Student Satisfaction With Professors during One to One Contacts. Caring, 37(30.10), 1-46.

${ }^{8}$ Rendon, L. I. (1994). Validating culturally diverse students: Toward a new model of learning and student development. Innovative higher education, 19(1), 33-51.

${ }^{9}$ Stewart, S. S., \& Rue, P. (1983). Commuter students: Definition and distribution. New Directions for Student Services, 1983(24), 3-8.

${ }^{10}$ Kasworm, C. E., \& Pike, G. R. (1994). Adult undergraduate students: Evaluating the appropriateness of a traditional model of academic performance. Research in Higher Education, 35(6), 689-710.

${ }^{11}$ Donaldson, J. F., \& Townsend, B. K. (2007). Higher education journals' discourse about adult undergraduate students. The Journal of Higher Education, 78(1), 27-50.

${ }^{12}$ Bean, J. P., \& Metzner, B. S. (1985). A conceptual model of nontraditional undergraduate student attrition. Review of educational Research, 55(4), 485-540.

${ }^{13}$ Metzner, B. S., \& Bean, J. P. (1987). The estimation of a conceptual model of nontraditional undergraduate student attrition. Research in higher education, 27(1), 15-38.

${ }^{14}$ Cuseo, J. (2000). "The Case For Careful Attention to the Transfer Transition," Presented at the Seventh National Conference on Students in Transition (sponsored by the National Resource Center for the First-Year Experience \& Students in Transition, University of South Carolina), Cincinnati, Ohio, USA, November 1-4, 2000, available at http://www.bccat.bc.ca/pubs/cuseo.pdf 
${ }^{15}$ Advisory Committee on Student Financial Assistance. (2008). Transition Matters: Community College to Bachelor's Degree, Washington, D.C.: Author. Retrieved September 11, 2009 (http://www.ed.gov/about/bdscomm/list/acsfa/transmattabb.pdf).

${ }^{16}$ Mobley, C., (2000). "Strengthening Transfer Advising and Retention (STAR): Initial Thoughts on Transfer Challenges." Internal Paper, Clemson University, Clemson, SC.

${ }^{17}$ Graham, S., \& Donaldson, J. F. (1999). Adult students' academic and intellectual development in college. Adult Education Quarterly, 49(3), 147-161.

${ }^{18}$ Dill, P. L., \& Henley, T. B. (1998). Stressors of college: A comparison of traditional and nontraditional students. The Journal of Psychology, 132(1), 25-32.

${ }^{19}$ Hall, B. (1992). "From Margins to Center? The Development and Purpose of Participatory Research," The American Sociologist, 23(4), 15-28.

${ }^{20}$ Wallace, S. (1980). Program Evaluation Report: Educational Marketing Program, July 1, 1979 to February 12, 1980.

${ }^{21}$ Roelfs, P. J. (1975). Teaching and counseling older college students. Findings.

${ }^{22}$ Greer, L. R. (1980). Persistence and Academic Success Among Non-Traditional Age Students at a Junior College. AIR Forum 1980 Paper.

${ }^{23}$ Franklin, P. (1981). COMMUTER STUDENTS. Education, 12(3), 117-215.

${ }^{24}$ Spitzer, T. M. (2000). Predictors of college success: A comparison of traditional and nontraditional age students. NASPA JOURNAL, 38(1), 82-98.

${ }^{25}$ Carney-Crompton, S., \& Tan, J. (2002). Support systems, psychological functioning, and academic performance of nontraditional female students. Adult Education Quarterly, 52(2), 140-154.

${ }^{26}$ Ohland, M.W., G. Zhang, B. Thorndyke, and T.J. Anderson, "The creation of the MultipleInstitution Database for Investigating Engineering Longitudinal Development (MIDFIELD)" Proc. Amer. Soc. Eng. Ed., Salt Lake City, Utah, June 2004.

${ }^{27}$ Long, R.A. (2012). MIDFIELD (The Multiple-Institution Database for Investigating Engineering Longitudinal Development). Available from: https://engineering.purdue.edu/MIDFIELD/

${ }^{28}$ U.S. Department of Education. 2007. IPEDS educational peer tool and peer analysis system. http://nces.ed.gov/ipedspas (accessed December 2007). Statistic based on 330 institutions nationwide (of 350) reported engineering degrees awarded in 2005.

${ }^{29}$ Horn, L. J., \& Carroll, C. D. (1996). Nontraditional Undergraduates: Trends in Enrollment from 1986 to 1992 and Persistence and Attainment among 1989-90 Beginning Postsecondary Students. Postsecondary Education Descriptive Analysis Reports. Statistical Analysis Report. US Government Printing Office, Superintendent of Documents, Mail Stop: SSOP, Washington, DC 20402-9328.

${ }^{30}$ Lord, S. M., Camacho, M. M., Layton, R. A., Long, R. A., Ohland, M. W., \& Wasburn, M. H. (2009). Who's persisting in engineering? A comparative analysis of female and male Asian, black, Hispanic, Native American, and white students. Journal of Women and Minorities in Science and Engineering, 15(2). 